\title{
Towards Reliability-Enhanced Mechanical Characterization of Non-Crimp Fabrics: How to Compare Two Force-Displacement Curves against a Null Material Hypothesis
}

\author{
Samia Sultana, Armin Rashidi, Mohammad Islam, Bryn Crawford, Abbas S. Milani* \\ Composites Research Network-Okanagan Laboratory, School of Engineering, University of British Columbia, \\ Kelowna, Canada \\ Email: *abbas.milani@ubc.ca
}

How to cite this paper: Sultana, S., Rashidi, A., Islam, M., Crawford, B. and Milani, A.S. (2019) Towards Reliability-Enhanced Mechanical Characterization of Non-Crimp Fabrics: How to Compare Two ForceDisplacement Curves against a Null Material Hypothesis. Open Journal of Composite Materials, 9, 164-182.

https://doi.org/10.4236/ojcm.2019.92008

Received: February 18, 2019

Accepted: April 12, 2019

Published: April 15, 2019

Copyright $\odot 2019$ by author(s) and Scientific Research Publishing Inc. This work is licensed under the Creative Commons Attribution International License (CC BY 4.0).

http://creativecommons.org/licenses/by/4.0/

\section{(c) (i) Open Access}

\begin{abstract}
Detailed characterization of fabric reinforcements is necessary to ensure the quality of manufactured composite parts, and subsequently to prevent structural failure during service. A lack of consensus and standardization exists in selecting test methods for the mechanical characterization of fabrics. Moreover, in reality, during any experimentation there are sources of uncertainties which may result in inconsistencies in the interpretation of data and the comparison of different testing methods. The aim of this article is to show how simple statistical data analysis methods may be used to enhance the characterization of composite fabrics under individual and combined loading modes while accounting for inherent material/test uncertainties. Results using a typical glass non-crimp fabric (NCF) show that, statistically, there are significant differences between the warp and weft direction responses of a presumably balanced NCF under all deformation modes, with weft yarns being generally stiffer. Moreover, the statistical significance of warp-weft couplings under both simultaneous and sequential biaxial-shear loading modes became statistically evident, when compared to a pure biaxial deformation.
\end{abstract}

\section{Keywords}

Textile Composites, Material Characterization, Statistical Methods

\section{Introduction}

Textile composite reinforcements have received considerable attention in high tech sectors for their multi-axial mechanical properties including high specific 
stiffness and impact strength [1] [2] [3]. Among different types of textile fiber architectures, woven fabrics are made by weaving warp and weft yarns into an interlaced repeated pattern. These materials have a sheet or mat-like shape and the fabric reinforcement is composed of thousand threads of fibers made of, e.g. carbon, glass, aramid, as well as natural fibers [1]. The fabric material properties are closely dependent on the fiber type and weave architecture such as plain, twill, satin, or basket [2]. On the other hand, non-crimp fabrics are sheet or web structures comprised of long fibers consolidated by bonds of different nature (e.g. chemical, stitching, or thermal) and are generally known to offer better handling/formability compared to their woven counterpart in specific applications due to the absence of crimp [3] [4].

Due to the high drapability of textile fabric reinforcements (woven or non-woven), they are capable of preforming into complex three-dimensional shapes before consolidating the composite with a resin [5]. The consolidation is often performed by means of resin transfer molding (RTM), resin injection molding (RIM) or other conventional polymer processing techniques [6] [7]. At the late 90s, researches also explored the use of thermo-stamping [8] and hydro-forming [9] to manufacture fabric reinforced composites [10]. Large components in today's composite industries are, for the most part, made by hand lay-up, press-molding [11] [12], automated tape laying, and resin-transfer molding [7].

\subsection{Characterization of Fabrics}

In practice, textile composite manufacturers still face high part failure rates due to the presence of defects in the final part such as voids, in-plane fiber waviness, wrinkles and cracking [13]. In particular, the complexity of forming fabrics into doubly-curved molds through processes such as press-forming has dragged researchers attention toward carefully characterizing fabrics' mechanical responses under fundamental deformation modes [10] [13]. The characterization may be done in macro, meso, and micro levels. Next to experimentation, researchers have also rigorously employed numerical modeling tools to characterize the fabrics deformation at the aforementioned material scales [14] [15] [16]. Among experimental characterization works, individual deformation modes (e.g. uniaxial tension, picture frame shear, bias extension shear, and biaxial tension) tests have been frequently employed to characterize fabric materials and to assess their homogeneity at macro/meso scales [17] [18] [19] [20].

During $2 \mathrm{D}$ and $3 \mathrm{D}$ characterization of dry fabric composite materials, the main goal is to understand the effect of material parameters on the formation of defects such as fiber misalignment and wrinkling [21]. Especially when forming doubly-curved parts, it has been known that understanding the in-plane shear behavior of the forming fabric is critical [22], and accordingly characterization setups such as bias extension and picture frame tests have been widely developed to investigate this shear response of fabrics. Normally, the weft and warp yarns have a relative angle of $90^{\circ}$ at the initial fabric configuration while during drap- 
ing this angle can drastically decrease, often to as low as $10^{\circ}$ depending on the mold shape and applied boundary conditions [21].

\subsection{Combined Loading Modes}

Recently, researchers have developed numerical and experimental studies to understand the effect of membrane forces on the shear response of fabrics under combined shear-tension loading modes, as these loadings are likely to occur in practice during manufacturing and/or service. Launay et al. [1] clearly observed the effect of tension on in-plane shear behavior of woven fabric by placing load sensors on four sides of the shear frame fixture. They observed a higher shear force when applying tension on the fabric. Similarly, Willems et al. [23] experimentally applied pre-tension on fabric using a biaxial-tension fixture while applying shear, reporting that the shear stiffness is not significantly affected by tensile forces. Other researchers [10] [24] [25] have employed biaxial bias-extension tests to induce shear tension coupling in fabrics. From the numerical studies [25] [26] [27], it has been noticed there are fuzzy deformation regions in such combined loading modes, making their theoretical analysis fairly complex.

A new fixture was also designed and manufactured by the authors' group to apply simultaneous shear-tension as well as shear-compression coupling modes on textile fabrics [28] [29]. Kashani et al. [30] employed this fixture to conduct a set of characterizations and captured the coupling coefficients in a glass woven fabrics by inducing biaxial tension in the yarns while shearing the fabric under trellising shear mode and performing local load-displacement data transformations. Nosrat-Nezami et al. [31] reported a similar shear-tension test fixture and performed characterization of coupling effects in carbon woven prepregs. Both groups of studies reported a substantial coupling effect specialty at high shear angles.

\subsection{Motivation and Objective of This Work}

Despite the widespread interest in manufacturing and application of textile composite reinforcements, as reviewed above, there still exists a lack of standardization on how to characterize and analyze fabric properties using different fixtures/loading modes, and to realistically predict the formation of associated defects such as wrinkling during forming trials. In addition, there is limited information on how to deal with unavoidable data inconsistencies during characterization, no matter which deformation mode. This article, as part of a larger research program at the Composites Research Network (CRN), aims to show how basic statistical methods may be adapted to draw unbiased comparisons between fabrics force-displacement characterization curves, under both individuals and combined loading modes. The rest of the manuscript has been structured as follows. Section 2 begins with a description of the selected test material and the characterization setup used along with the statistical analysis framework. Results and discussions are presented in Section 3, followed by concluding remarks in Section 4. 


\section{Material and Methods}

\subsection{Fabric Material}

A heavy triaxial $[0,90,0]$ dry fiberglass non-crimp fabric with polyester stiches (under TG-54-N commercial name) was opted for experiments. Table 1 presents a summary of the material specifications, and Figure 1 shows an image of the fabric structure. Per convention, the fabric roll direction determined the warp yarns (Figure 1).

\subsection{Experimental Device}

The main aim of using the designed combined loading fixture (Figure 2) was to be able to run the biaxial extension on the fabric while sequentially or simultaneously applying different shear modes (e.g. picture frame shear and/or circular/sliding shear). The instrument is controlled via six motors, load cells, data acquisition systems, which are all connected to the LabView [32]. For measuring the applied loads in the biaxial directions, two load cells were installed between the jaws and the lead screw plate, which could measure in-line forces in each direction. To apply shear for picture frame direction, a smaller synchronous motor was installed, which applies the load at one diagonal corner of the fixture (Figure 2), up to a maximum of $1000 \mathrm{~N}$. In order to measure the load during the rotational shear mode, another DC motor was installed as shown in Figure 2. For displacement measurement in biaxial and shear directions, high-resolution linear variable differential transducers (LVDTs) were used. In the biaxial direction, the LVDT provided axial displacement, and in the picture frame direction, the LVDT provided shear displacement. As fiber slippage was known to be one of the major difficulties in fabric tests [28] [29] [30] [31], which occurs between the fibers and clamps, a custom-designed needle system along with proper mounting contact was used (Figure 3 ). This clamping system could effectively eliminate the slippage of the test samples while allowing the yarns to freely rotate along needles under shear modes; for more details on the design of these clamp needles, please refer to [30].

Table 1. Description of the fabric test material (adapted from TDS-Texonic JB Martin).

\begin{tabular}{cc}
\hline Commercial code & E-Glass TG-54-N \\
\hline Nominal weight $\left(\mathrm{g} / \mathrm{m}^{2}\right)$ & 1824 \\
Standard roll length $(\mathrm{m})$ & 35 \\
Resin compatibility & Polyester, Venylester, Epoxy \\
Compressed thickness $(\mathrm{mm})$ & 1.52 \\
Wet layup thickness $(\mathrm{mm})$ & 2 \\
Warp fill ratio $(\%)$ & 52 \\
Warp end counts $($ per $\mathrm{cm})$ & 8 \\
Weft end counts $($ per $\mathrm{cm})$ & 11.4 \\
\hline
\end{tabular}




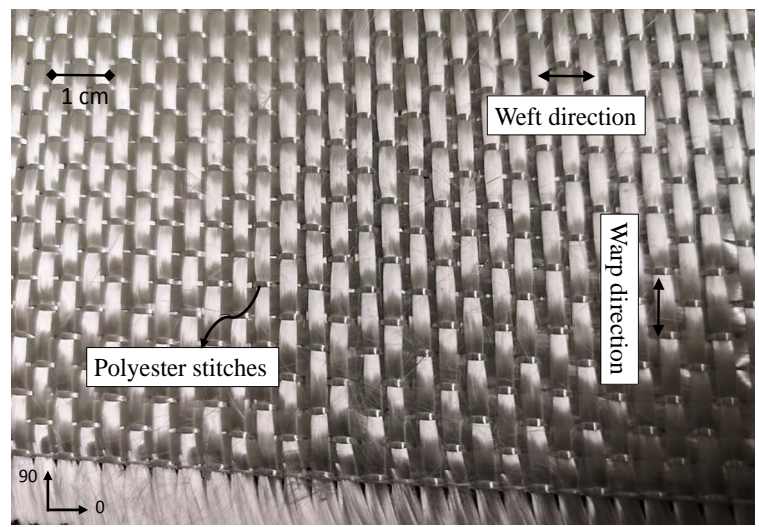

Figure 1. E-Glass TG-54-N non-woven fabric.

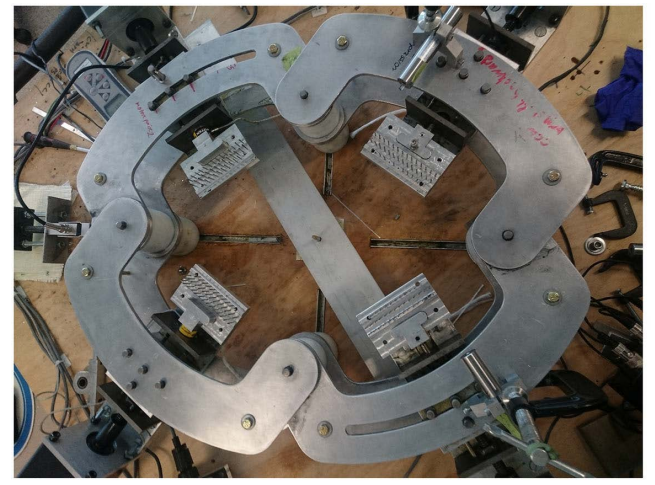

Figure 2. The combined loading test fixture employed for the characterization tests.

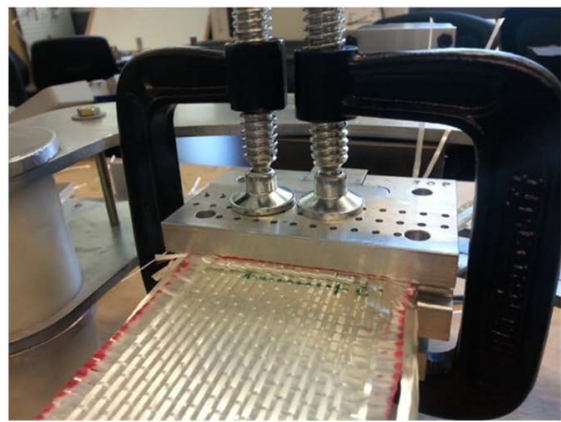

(a)

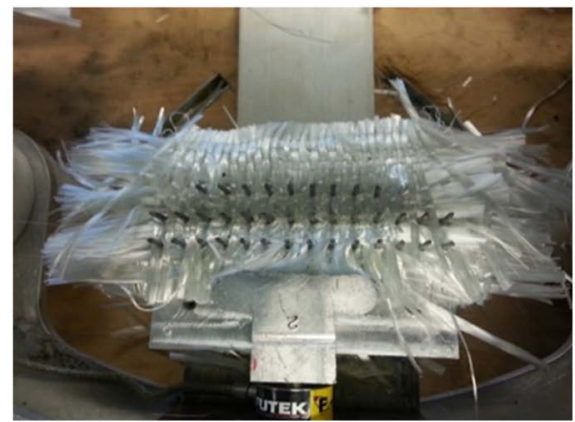

(b)

Figure 3. (a) Fabric clamping with needle jaw and C-clamps to ensure proper contact and no slippage condition; (b) a close-up view under the jaw.

Figure 4 schematically shows three fundamental deformation mechanisms induced by the combined loading test fixture. By combining these three fundamental modes, the instrument in total could be run in seven deformation modes.

Biaxial tension mode: De-crimping of warp and weft tows when extended concurrently prompts non-linearities in the mechanical response of the fabrics [32] [33]. More specifically, because of the inter-locked architecture, the tensioning/de-crimping in the warp and weft yarns become inter-dependent and yield complex meso-level coupled deformations. As discussed in Section 1, bi- 
axial properties of several fabrics have been tested in the past research works [23] [34] [35]. Relating to the same efforts, the present research used the pure biaxial mode using the fiberglass fabric described in Section 2.1.

Picture frame shear mode: The schematic of pure shear (picture frame/PF) definition is shown in Figure 5. Theoretically, the initial square (blue) region of the fabric cell is changed to a rhomboid shape upon loading. Based upon the work of Komeili et al. [36] [37], it is critical to recognize the fabric's shear behavior with and without yarns rigid body rotation as follows.

Rotational shear mode or trellising: Ordinarily, a change in angle between adjacent warp and weft yarns is referred to as shear angle in the fabrics. However, shear angle can likewise happen with rigid body rotation of yarns (Figure 6) in lieu of intra-yarn deformation and pure (picture frame) mode [30]. The circular shear (CS) mode is a rather new mode of deformation considered by some researchers in the literature due to its application in e.g. inflatable tubes [28]. The fundamental difference between these two shear modes is that in the rotational/circular mode the yarns at crossover do not retain the same contact points after loading (Figure 6). Also under this mode, the intra-yarn shear would be present [30].

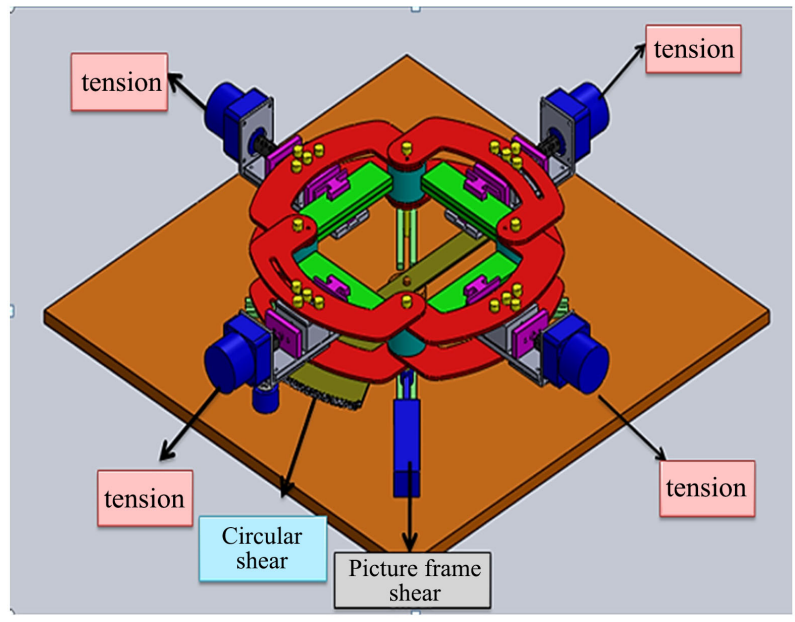

Figure 4. Example of the induced deformation modes by the combined loading test fixture.

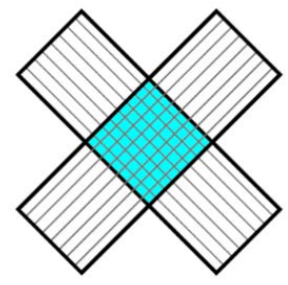

(a)

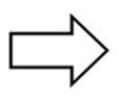

Figure 5. The schematic of pure shear mode showing shear deformation without yarn slippage; (a) initial region before the picture frame shear, (b) deformed region after the picture frame shear. 


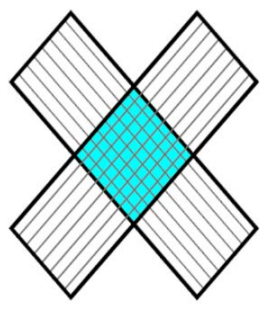

(a)

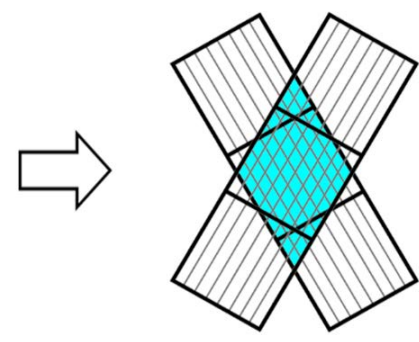

(b)

Figure 6. The schematic of circular or rotational (sliding) shear; (a) initial region before the circular shear, (b) deformed region after the circular shear.

\subsection{ANOVA Analysis for Comparing Two Characterization Tests against a Null Hypothesis}

The analysis of variance (ANOVA) is one type of hypothesis testing technique (among many others) that has found a great application in experimental data analyses [38] [39] [40]. Material characterization data is often used by designers to make decisions on the choice of optimum material/process/system based on associated null hypotheses. Rejecting a null hypothesis is statistically considered significant when the probability P-value is less than 0.05 [38] [39]. However, the acceptance of the null hypothesis occurs when the probability $\mathrm{P}$-value is higher than e.g. 0.05. During the experiments under different deformation modes, the axial displacement and/or shear angle were applied to the test fabric at different deformation modes while the axial forces were observed at the output (i.e. displacement controlled tests). Considering the setup in Section 2.3, every test mode was expected to experience some level of noise, due to e.g. sample preparation and handling errors, LVDT sensor errors, and fabric miss-clamping, inherent fiber misalignment variation from one sample to another, among others (Figure 7). Under such a multitude of noise factors, statistically, one should expect that the output measurements have random variations. Hence, the significant interpretations from the tests (e.g. the effect of deformation mode, warp-weft coupling effect, etc.) must be analyzed under a statistical hypothesis testing framework.

In order to account for random noises during the tests and find the correct significance of force-displacement data from different tests, two-factor ANOVA analysis was considered, with interaction terms representing the random error. Namely, one factor was considered to be the controlled displacement (whose levels can be arbitrarily selected from the response curve, as exemplified in Figure 8), and the other factor was the main targeted treatment factor, often with two levels (e.g. when comparing two types of deformation modes such as shear vs. simultaneous shear-tension, or when assessing the effect of reinforcement direction in weft vs. warp in a given test mode, etc.). More specifically, in the example of Figure 8 between the two deformation modes, at each given displacement level (or shear angle), there are two means which are considered as $\mu_{1}$ and $\mu_{2}$. The test hypotheses are: $\mathrm{H}_{0}: \mu_{1}=\mu_{2}$ and $\mathrm{H}_{1}: \mu_{1} \neq \mu_{2}$. The means of the 
material response in the two deformation modes are statistically the same when the corresponding $\mathrm{P}$-value is greater than 0.05 and the null hypothesis $\mathrm{H}_{0}$ should not be rejected [40]. On the other hand, the means of the material response in the two deformation modes would be different when the P-value is lower than 0.05. Table 2 outlines one example of ANOVA statistical analysis at two deformation modes, performed at Minitab ${ }^{\circledast}$, where the targeted null hypothesis would dictate that, "the force response in the two tested modes of fabric deformation is statistically identical due to the presence of noise". Only with a P-value less than $5 \%$ this hypothesis may be rejected for further design decisions. The validity of the ANOVA assumptions (namely the normality and contact variance of residual errors [40]) were checked for each performed case (see the Appendix).

Table 2. Framework for ANOVA analysis in an example with two types of deformation modes (i.e. as factor 1 with two levels) and eight selected displacement levels (as factor 2). The tests outcomes (measurements) are assumed to be the force values.

\begin{tabular}{cccc}
\hline \multicolumn{2}{c}{ Mode 1 } & \multicolumn{3}{c}{ Mode 2 } \\
\hline Displacement & Normalized force & Displacement & Normalized force \\
\hline d1 & f1 & D1 & F1 \\
d2 & f2 & D2 & F2 \\
d3 & f3 & D3 & F3 \\
d4 & f4 & D4 & F4 \\
d5 & f5 & D5 & F5 \\
d6 & f6 & D6 & F6 \\
d7 & f7 & D7 & F7 \\
d8 & f8 & D8 & F8 \\
\hline
\end{tabular}

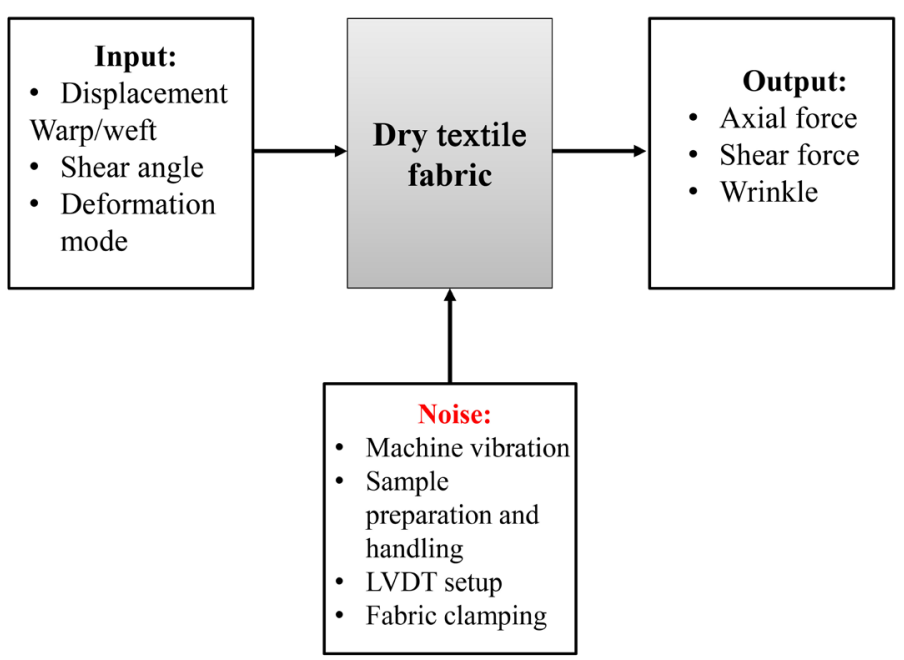

Figure 7. Schematic of the experimental input, output and noise to assess the statistical importance of material/test design factors. 


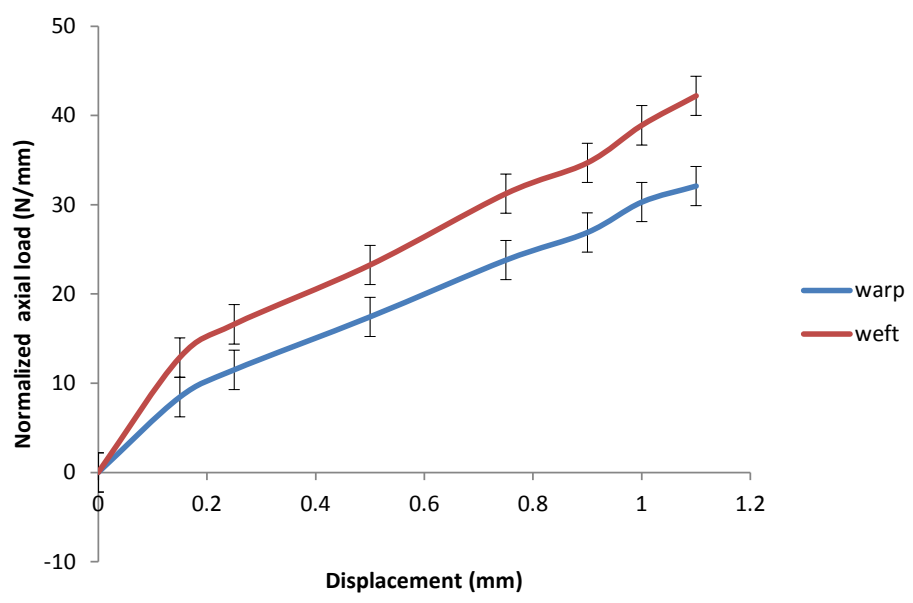

Figure 8. Schematic of the experimental input, output, and noise to assess the statistical.

\section{Results and Discussions}

\subsection{Biaxial Tension Tests}

The force-displacement results under the pure biaxial mode for the test material are shown in Figure 9. For both the warp and weft directions, the normalized axial force increase with applying the displacement. At the $1.1 \mathrm{~mm}$ displacement, the biaxial forces in the warp and weft directions were $60.7 \mathrm{~N} / \mathrm{yarn}$ and $78.9 \mathrm{~N} /$ yarn, respectively (i.e. $~ 24 \%$ difference). The DIC camera observation (Figure 9) also showed that the axial displacement at this instant was around $1.08 \mathrm{~mm}$ (near to the displacement of $1.1 \mathrm{~mm}$ based in Figure 9), hence giving confidence in the reliability of the LVDT values. The statistical analysis of this biaxial mode resulted in rejecting the null hypothesis, meaning that the biaxial responses of the warp and weft yarns are significantly different for the test non-crimp fabric (P-value $0.008<5 \%)$.

\subsection{Simultaneous Biaxial Tension and Shear Modes}

Different experimental results of the simultaneous biaxial tension and shear modes are shown in Figure 10. It can be observed that the material resistance to deform is higher under the concurrent circular shear and picture frame shear along with the biaxial loading, for both warp and weft directions (P-values < 5\%). Similar to the pure biaxial mode in Section 3.1, here the weft response in all simultaneous deformation modes was also higher than warp. The simultaneous picture frame-biaxial weft response showed the highest axial force per yarn at the displacement of $1.1 \mathrm{~mm}$. With circular shear affecting the simultaneous mode, the warp property (blue line in Figure 10) showed the lowest magnitude among the four tested combined loading modes. The imposed shear deformation along the yarns increases the lateral (side to side) contact forces as well as between filaments, and hence increases the fabric rigidity [30]. The magnitude of these contact forces is anticipated to be higher in the picture frame (PF) mode when compared to the circular shear, due to the intensified fiber interactions resulting from thining of the yarns in the width direction in the PF mode [30]. 

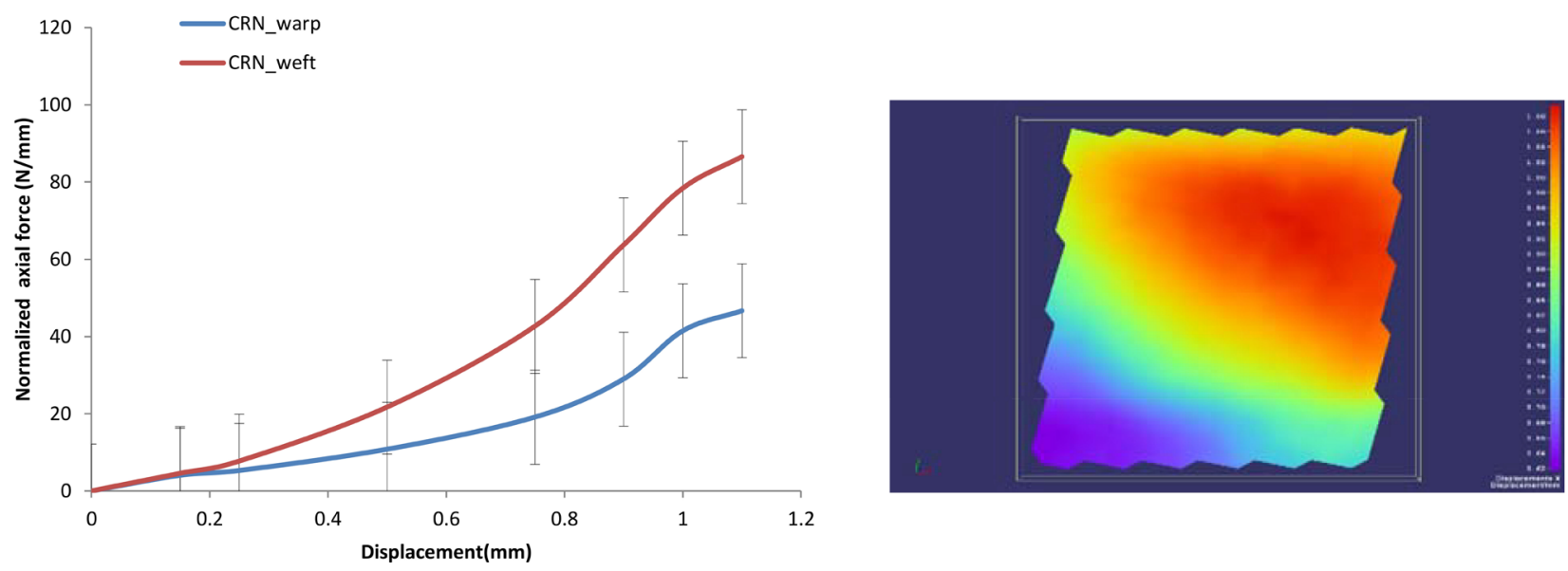

Figure 9. (a) Pure biaxial deformation of the fiberglass fabric in the warp and weft directions; (b) The axial displacement measured by digital image correlation (DIC) in the weft direction.

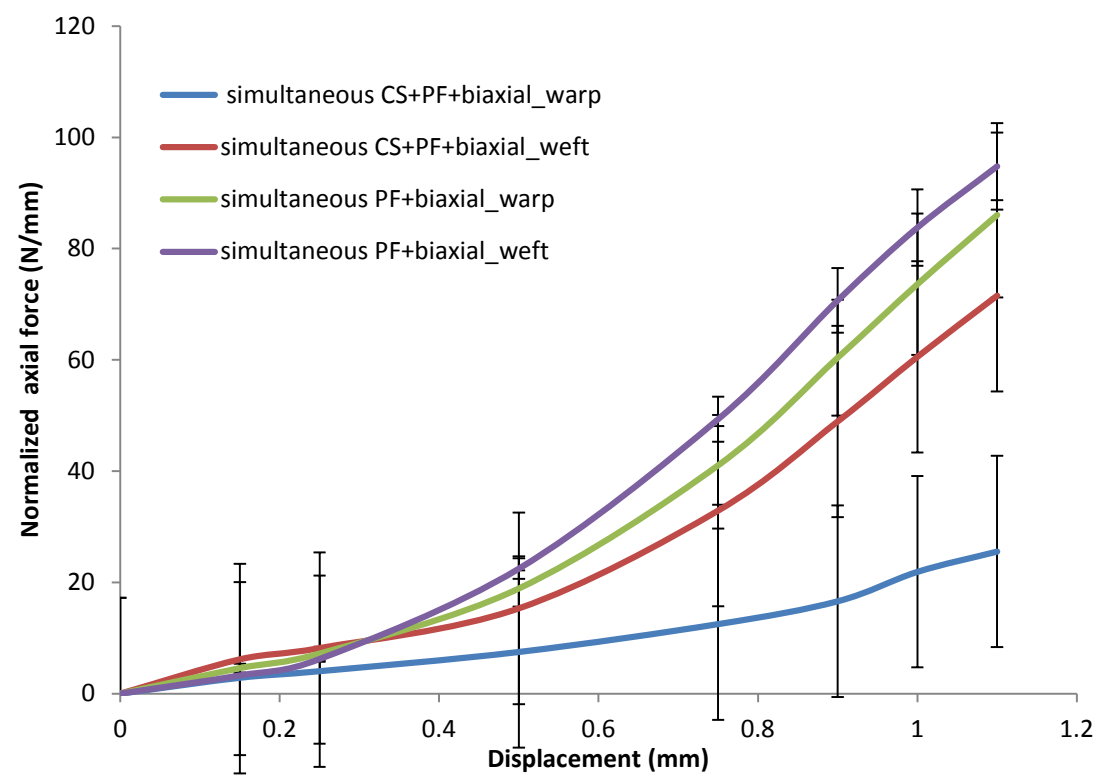

Figure 10. The biaxial response of the fiberglass fabric in the warp and weft directions under simultaneous picture frame-biaxial tension modes.

\subsection{Statistical Evidence of Coupling Effect: Comparison between Biaxial and Simultaneous Loading Modes}

Composites may undergo multiple loading modes during forming or actual service conditions (e.g. unbalanced blank holding forces, the weight of other sub-components, skewed impacts with external objects, etc.). Hence, characterizing the simultaneous biaxial tension, circular and picture frame shear of reinforcement fabrics would be essential to better predict the behavior of consolidated final parts [37] [41]-[46]. Combining test data in Sections 3.1 and 3.2, in this section, the pure biaxial and simultaneous picture frame $(\mathrm{PF})+$ biaxial modes were compared and analyzed in Figure 11. According to this figure, the yarns behavior under simultaneous shear-tension is found to be much higher 
than that in the pure biaxial mode (P-value of 0.025 and 0.03 for the warp and the weft related tests, accordingly). In addition, the weft yarns under pure and simultaneous loading modes showed a statistically higher axial force than warp; also note from the material specifications, Table 1, that the warp end count of 8 per $\mathrm{cm}$ which is lower than the weft end count $(11$ per $\mathrm{cm})$; Figure 1 also showed that warp yarns are normally wavier than the weft yarns.

The ANOVA analyses under these tests suggest that by applying shear while tensioning the yarns, their axial stiffness is significantly changing (i.e. coupling effect of shear on tensile behavior of the fabrics). Next, a similar coupling analysis was performed between the pure biaxial mode and the simultaneous CS + PF + biaxial mode. According to Figure 12, shear-tension coupling in simultaneous $\mathrm{CS}+\mathrm{PF}+$ biaxial is found to be the highest in the weft direction. However, the warp axial force was lower for simultaneous CS + PF + biaxial than the pure biaxial mode. The reason of this observation may be that during the latter test, the circular shear (rotation) was applied to warp yarns, hence CS + PF + biaxial warp was at a larger angle with the corresponding motor normal force direction. The ANOVA analysis between the above two deformation modes was carried out for both warp and weft directions. The null hypotheses were rejected in both cases as P-values were found to be 0.014 for weft yarns and 0.001 for the warp yarns, respectively. ANOVA concluded that the combined PF + CF shear modes significantly affect the biaxial response of the fabric and hence a severe coupling effect.

\subsection{Assessing the Effect of Sequential Loading: A PF Shear Followed by Biaxial Tension}

During the molding of fabrics, they may experience some tension or shear sequentially depending on how the manufacturing process is designed by engineers (e.g. handling of fabrics before molding may induce some pre-shear, whereas the installment of the fabric in a blank-holder may induce some pre-tension). Here a case of pre-shearing followed by biaxial deformation was considered. Namely the test fabric was exposed to a $15^{\circ}$ picture frame shear and then it undertook the biaxial tension loading. Figure 13 illustrates results of this test, both at warp and weft directions. The sheared and then biaxially tensioned fabric overall showed higher tensile forces than the tensioned sample under pure biaxial mode; the P-value for this comparison in the weft direction was $1.36 \times$ $10^{-5}$ and in the warp direction it was 0.008 , which means the corresponding null hypotheses were strongly rejected and the pre-shear has a notable effect on both warp and weft effective moduli of the material.

\section{Concluding Remarks}

This article aimed to adopt a simple statistical framework for comparing various material characterization tests for woven fabric composites, and accordingly contribute to the ongoing efforts toward standardization of these test methods 


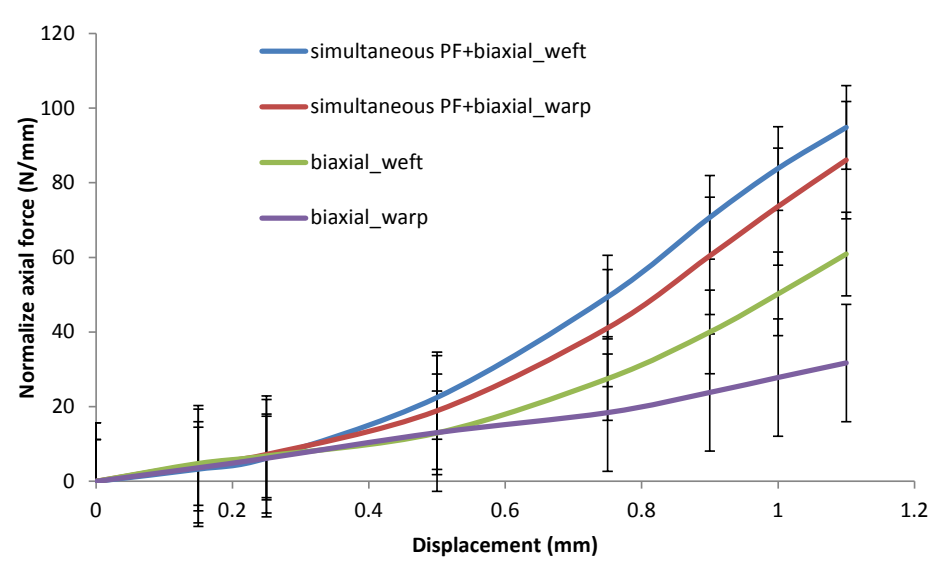

Figure 11. Shear-tension coupling study by comparing simultaneous picture frame shear-biaxial tension, with pure biaxial deformation.

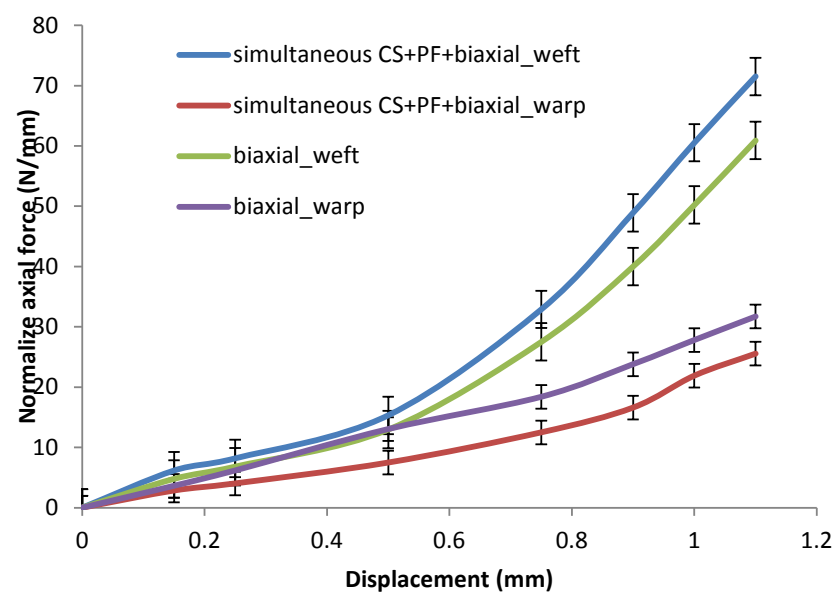

Figure 12. Shear-tension coupling study by comparing simultaneous circular shear-picture frame shear-biaxial tension, with pure biaxial deformation.

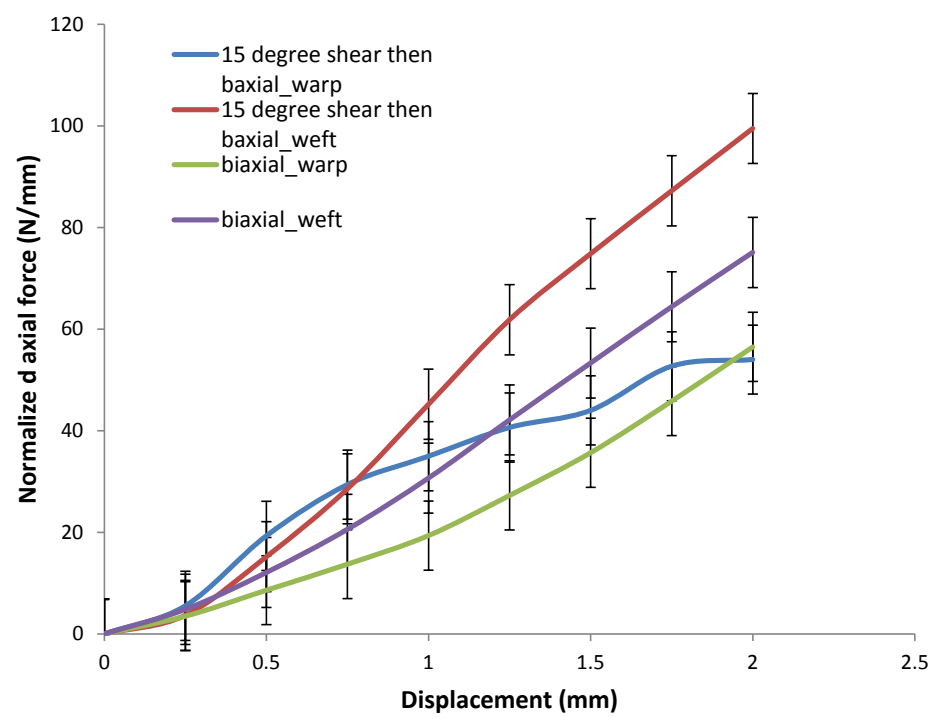

Figure 13. Sequential coupling study (15o shear then biaxial) and its comparison with the pure biaxial deformation. 
and capturing their differences. The statistical analysis throughout the performed tests was found to be useful in confirming the reliability of general observations from the experiments, without which final design interpretations/decision makings may be subjective. ANOVA results under the performed test modes and their comparisons revealed that:

- For biaxial deformation mode, the warp and weft yarn properties were significantly different (P-value $<0.008)$, suggesting an unbalanced fabric behavior at warp and weft directions.

- Weft yarns were stiffer than warp yarns in their axial response under all tested individual and combined deformation modes, including the picture frame shear + circular shear + biaxial tension.

- Simultaneous picture frame shear-biaxial tension mode, as well as its sequential version, showed higher force magnitudes compared to the pure biaxial mode, suggesting a significant effect of meso-level couplings within the fabric (see [46] for details).

The methods presented here were for quasi-static deformation rates. For high-speed tests, such as those for impact characterization, the material response rate dependency should be additionally accounted for, e.g. possibly by using hypothesis testing with time-series data. Characterization results may also be used in conjunction with future simulations of fabrics for 3D draping processes, especially in the presence of coupling effects on doubly-curved mould surfaces. The enhanced reliability of such simulations can result in more accurate prediction and prevention of high stresses or defected regions in the final part; e.g. by providing optimum levels of membrane pre-stresses to each direction of yarns or by using blank holders geometry modifications as recently suggested in [42] [43] [44] [45] [46].

\section{Acknowledgements}

The authors would like to acknowledge financial support from the Natural Sciences and Engineering Research Council (NSERC) of Canada. Thanks are also due to Campion Inc. for providing significant in-kind contribution for this research. The authors are grateful to their colleagues at the Composites Research Network as well the City College of New York for stimulating discussions.

\section{Conflicts of Interest}

The authors declare no conflicts of interest regarding the publication of this paper.

\section{References}

[1] Launay, J., Hivet, G., Duong, A.V. and Boisse, P. (2008) Experimental Analysis of the Influence of Tensions on in Plane Shear Behaviour of Woven Composite Reinforcements. Composites Science and Technology, 68, 506-515. https://doi.org/10.1016/j.compscitech.2007.06.021

[2] Strong, A.B. (2008) Fundamentals of Composites Manufacturing: Materials, Meth- 
ods and Applications.

[3] Edgren, F., Mattsson, D., Asp, L.E. and Varna, J. (2004) Formation of Damage and Its Effects on Non-Crimp Fabric Reinforced Composites Loaded in Tension. Composites Science and Technology, 64, 675-692. https://doi.org/10.1016/S0266-3538(03)00292-6

[4] Creech, G. and Pickett, A. (2006) Meso-Modelling of Non-Crimp Fabric Composites for Coupled Drape and Failure Analysis. Journal of Materials Science, 41, 6725-6736. https://doi.org/10.1007/s10853-006-0213-6

[5] Guagliano, M. and Riva, E. (2001) Mechanical Behaviour Prediction in Plain Weave Composites. The Journal of Strain Analysis for Engineering Design, 36, 153-162. https://doi.org/10.1243/0309324011512702

[6] Cao, J., Akkerman, R., Boisse, P., Chen, J., Cheng, H., De Graaf, E., Gorczyca, J., Harrison, P., Hivet, G. and Launay, J. (2008) Characterization of Mechanical Behavior of Woven Fabrics: Experimental Methods and Benchmark Results. Composites Part A: Applied Science and Manufacturing, 39, 1037-1053. https://doi.org/10.1016/j.compositesa.2008.02.016

[7] Zhao, X., Liu, G., Gong, M., Song, J., Zhao, Y. and Du, S. (2018) Effect of Tackification on In-Plane Shear Behaviours of Biaxial Woven Fabrics in Bias Extension Test: Experiments and Finite Element Modeling. Composites Science and Technology, 159, 33-41. https://doi.org/10.1016/j.compscitech.2018.02.016

[8] Sargent, J., Chen, J., Sherwood, J., Cao, J., Boisse, P., Willem, A., Vanclooster, K., Lomov, S.V., Khan, M. and Mabrouki, T. (2010) Benchmark Study of Finite Element Models for Simulating the Thermostamping of Woven-Fabric Reinforced Composites. International Journal of Material Forming, 3, 683-686.

https://doi.org/10.1007/s12289-010-0862-5

[9] Zampaloni, M.A., Pourboghrat, F. and Yu, W. (2004) Stamp Thermo-Hydroforming: A New Method for Processing Fiber-Reinforced Thermoplastic Composite Sheets. Journal of Thermoplastic Composite Materials, 17, 31-50. https://doi.org/10.1177/0892705704038219

[10] Abdiwi, F., Harrison, P. and Yu, W. (2013) Modelling the Shear-Tension Coupling of Woven Engineering Fabrics. Advances in Materials Science and Engineering, 2013, Article ID: 786769. https://doi.org/10.1155/2013/786769

[11] Taha, I., Abdin, Y. and Ebeid, S. (2013) Comparison of Picture Frame and Bias-Extension Tests for the Characterization of Shear Behaviour in Natural Fibre Woven Fabrics. Fibers and Polymers, 14, 338-344. https://doi.org/10.1007/s12221-013-0338-6

[12] Ray, D., Bose, N.R., Mohanty, A.K. and Misra, M. (2007) Modification of the Dynamic Damping Behaviour of Jute/Vinylester Composites with Latex Interlayer. Composites Part B: Engineering, 38, 380-385. https://doi.org/10.1016/j.compositesb.2006.06.011

[13] Yin, H., Peng, X., Du, T. and Guo, Z. (2014) Draping of Plain Woven Carbon Fabrics over a Double-Curvature Mold. Composites Science and Technology, 92, 64-69. https://doi.org/10.1016/j.compscitech.2013.12.013

[14] Boisse, P., Borr, M., Buet, K. and Cherouat, A. (1997) Finite Element Simulations of Textile Composite Forming Including the Biaxial Fabric Behaviour. Composites Part B: Engineering, 28, 453-464. https://doi.org/10.1016/S1359-8368(96)00067-4

[15] Chen, J.W., Zhao, B., Chen, W.J., Wang, M.Y., Guan, X.Y. and Wu, S.H. (2018) Response Surface Analysis of Biaxial Mechanical Properties and Elastic Parameters for Woven Fabric Composites. Journal of Industrial Textiles, in press. 
[16] Kawabata, S. and Niwa, M. (1989) Fabric Performance in Clothing and Clothing Manufacture. Journal of the Textile Institute, 80, 19-50. https://doi.org/10.1080/00405008908659184

[17] Chen, W., Gao, C., Zhang, D., Wang, L. and Qiu, Z. (2018) A New Biaxial Tensile Shear Test Method to Measure Shear Behaviour of Coated Fabrics for Architectural Use. Composite Structures, 203, 943-951. https://doi.org/10.1016/j.compstruct.2018.06.063

[18] Peng, X. and Cao, J. (2002) A Dual Homogenization and Finite Element Approach for Material Characterization of Textile Composites. Composites Part B: Engineering, 33, 45-56. https://doi.org/10.1016/S1359-8368(01)00052-X

[19] Nishi, M., Hirashima, T. and Kurashiki, T. (2014) Textile Composite Reinforcement Forming Analysis Considering Out-of-Plane Bending Stiffness and Tension Dependent In-Plane Shear Behavior. ECCM16-16th European Conference on Composite Materials, Seville, Spain, 22-26 June 2014, 22-26.

[20] Döbrich, O., Gereke, T., Diestel, O., Krzywinski, S. and Cherif, C. (2014) Decoupling the Bending Behavior and the Membrane Properties of Finite Shell Elements for a Correct Description of the Mechanical Behavior of Textiles with a Laminate Formulation. Journal of Industrial Textiles, 44, 70-84.

https://doi.org/10.1177/1528083713477442

[21] Gereke, T., Döbrich, O., Hübner, M. and Cherif, C. (2013) Experimental and Computational Composite Textile Reinforcement Forming: A Review. Composites Part A: Applied Science and Manufacturing, 46, 1-10.

https://doi.org/10.1016/j.compositesa.2012.10.004

[22] Colman, A., Bridgens, B., Gosling, P., Jou, G. and Hsu, X. (2014) Shear Behaviour of Architectural Fabrics Subjected to Biaxial Tensile Loads. Composites Part A: Applied Science and Manufacturing, 66, 163-174. https://doi.org/10.1016/j.compositesa.2014.07.015

[23] Willems, A., Lomov, S.V., Verpoest, I. and Vandepitte, D. (2008) Optical Strain Fields in Shear and Tensile Testing of Textile Reinforcements. Composites Science and Technology, 68, 807-819. https://doi.org/10.1016/j.compscitech.2007.08.018

[24] Harrison, P., Abdiwi, F., Guo, Z., Potluri, P. and Yu, W. (2012) Characterising the Shear-Tension Coupling and Wrinkling Behaviour of Woven Engineering Fabrics. Composites Part A: Applied Science and Manufacturing, 43, 903-914. https://doi.org/10.1016/j.compositesa.2012.01.024

[25] Harrison, P. (2012) Normalisation of Biaxial Bias Extension Test Results Considering Shear Tension Coupling. Composites Part A: Applied Science and Manufacturing, 43, 1546-1554. https://doi.org/10.1016/j.compositesa.2012.04.014

[26] Lee, W., Byun, J., Um, M., Cao, J. and Boisse, P. (2009) Coupled Non-Orthogonal Constitutive Model for Woven Fabric Composites. 17 th International Conference on Composite Materials, ICCM-17, Edinburgh, United Kingdom, 27-29 July 2009, 27-29.

[27] Lee, W., Um, M., Byun, J., Boisse, P. and Cao, J. (2010) Numerical Study on Thermo-Stamping of Woven Fabric Composites Based on Double-Dome Stretch Forming. International Journal of Material Forming, 3, 1217-1227. https://doi.org/10.1007/s12289-009-0668-5

[28] Cavallaro, P.V., Quigley, C.J., Johnson, A.R. and Sadegh, A.M. (2004) Effects of Coupled Biaxial Tension and Shear Stresses on Decrimping Behavior in Pressurized Woven Fabric. ASME 2004 International Mechanical Engineering Congress and Exposition, Anaheim, CA, 13-19 November 2004, 13-21. 
[29] Cavallaro, P.V., Sadegh, A.M. and Quigley, C.J. (2007) Decrimping Behavior of Uncoated Plain-Woven Fabrics Subjected to Combined Biaxial Tension and Shear Stresses. Textile Research Journal, 77, 403-416. https://doi.org/10.1177/0040517507080258

[30] Kashani, M.H., Rashidi, A., Crawford, B. and Milani, A. (2016) Analysis of a TwoWay Tension-Shear Coupling in Woven Fabrics under Combined Loading Tests: Global to Local Transformation of Non-Orthogonal Normalized Forces and Displacements. Composites Part A: Applied Science and Manufacturing, 88, 272-285. https://doi.org/10.1016/j.compositesa.2016.06.004

[31] Nosrat-Nezami, F., Gereke, T., Eberdt, C. and Cherif, C. (2014) Characterisation of the Shear-Tension Coupling of Carbon-Fibre Fabric under Controlled Membrane Tensions for Precise Simulative Predictions of Industrial Preforming Processes. Composites Part A: Applied Science and Manufacturing, 67, 131-139. https://doi.org/10.1016/j.compositesa.2014.08.030

[32] http://www.ni.com/labview/

[33] Boisse, P., Hamila, N., Vidal-Sallé, E. and Dumont, F. (2011) Simulation of Wrinkling during Textile Composite Reinforcement Forming. Influence of Tensile, In-Plane Shear and Bending Stiffnesses. Composites Science and Technology, 71, 683-692. https://doi.org/10.1016/j.compscitech.2011.01.011

[34] Buet-Gautier, K. and Boisse, P. (2001) Experimental Analysis and Modeling of Biaxial Mechanical Behavior of Woven Composite Reinforcements. Experimental Mechanics, 41, 260-269. https://doi.org/10.1007/BF02323143

[35] Carvelli, V., Corazza, C. and Poggi, C. (2008) Mechanical Modelling of Monofilament Technical Textiles. Computational Materials Science, 42, 679-691.

https://doi.org/10.1016/j.commatsci.2007.10.003

[36] Komeili, M. and Milani, A. (2013) An Elaboration on the Shear Characterization of Dry Woven Fabrics Using Trellising Tests. Polymer Composites, 34, 359-367. https://doi.org/10.1002/pc.22347

[37] Komeili, M. and Milani, A. (2016) On Effect of Shear-Tension Coupling in Forming Simulation of Woven Fabric Reinforcements. Composites Part B: Engineering, 99, 17-29. https://doi.org/10.1016/j.compositesb.2016.05.004

[38] Bilisik, K. (2011) Pull-Out Properties of Polyester Woven Fabrics: Effects of Softening Agent and Inter-Lacement on Single and Multiple Yarn Pull-Out Forces and Analysis by Statistical Model. Fibers and Polymers, 12, 1106-1118. https://doi.org/10.1007/s12221-011-1106-0

[39] Işık, B. and Ekici, E. (2010) Experimental Investigations of Damage Analysis in Drilling of Woven Glass Fiber-Reinforced Plastic Composites. The International Journal of Advanced Manufacturing Technology, 49, 861-869. https://doi.org/10.1007/s00170-009-2440-x

[40] Montgomery DC. (1991) Design and Analysis of Experiments.

[41] Cavallaro, P. (2016) Effects of Weave Styles and Crimp Gradients in Woven Kevlar/Epoxy Composites. Experimental Mechanics, 56, 617-635. https://doi.org/10.1007/s11340-015-0075-4

[42] Rashidi, A. and Milani, A. (2018) Passive Control of Wrinkles in Woven Fabric Preforms Using a Geometrical Modification of Blank Holders. Composites Part A: Applied Science and Manufacturing, 105, 300-309. https://doi.org/10.1016/j.compositesa.2017.11.023

[43] Rashidi, A. and Milani, A.A. (2018) Multi-Step Biaxial Bias Extension Test for 
Wrinkling/De-Wrinkling Characterization of Woven Fabrics: Towards Optimum Forming Design Guidelines. Materials and Design, 146, 273-285.

https://doi.org/10.1016/j.matdes.2018.02.075

[44] Montazerian, H., Rashidi, A., Hoorfar, M. and Milani, A.S. (2019) A Frameless Picture Frame Test with Embedded Sensor: Mitigation of Imperfections in Shear Characterization of Woven Fabrics. Composite Structures, 211, 112-124.

https://doi.org/10.1016/j.compstruct.2018.11.096

[45] Rashidi, A. and Milani, A. (2016) Characterization of Wrinkling and De-Wrinkling Behaviour of Woven Fabrics Using a Multi-Step Biaxial Bias Extension Test. ECCM17-17th European Conference on Composite Materials, Munich, Germany, 26-30 June 2016, 26-30.

[46] Kashani, M.H., Hosseini, A., Sassani, F., Ko, F.K. and Milani, A.S. (2018) The Role of Intra-Yarn Shear in Integrated Multi-Scale Deformation Analyses of Woven Fabrics: A Critical Review. Critical Reviews in Solid State and Materials Sciences, 43, 213-232. https://doi.org/10.1080/10408436.2017.1342597

[47] Schultz, B.B. (1985) Levene's Test for Relative Variation. Systematic Zoology, 34, 449-456. 


\section{Appendix}

In order to use the standard ANOVA in experimental data analysis, the following main assumptions need to be checked [40]:

- the samples/data points are independent;

- each sample group is drawn from a normally distributed population and;

- all data populations have a common variance; i.e. the variances of the error distributions among the populations are homogenous.

The first assumption is readily verified in the current study as the fabric samples were cut independently from the larger fabric rolls and the tests were performed in no specific order. The following section provides the detailed results for testing the normality and common variance assumptions for an example case where the biaxial mode was compared with the simultaneous biaxial + shear mode (i.e. Section 3.3). The ANOVA table for this case (Table A1) clearly indicated higher F-ratios compared to critical F-ratio (i.e. P-values $<5 \%$ ), for both factors of 1) deformation mode type and 2) the displacement level (i.e. effect of large deformation on varying the reaction load magnitude). The quantile-quantile plot or q-q plot plots of the residuals for this ANOVA is depicted in Figure A1, showing the residuals are approximately lined up with the theoretically-driven normal values. Next, the homogeneity of error variances was assessed using the Levene's test, adapted to the two-way ANOVA. The result in Table A2 suggests that the constant variance assumption of the ANOVA can be justified since the P-value $>5 \%$ (i.e. the null hypothesis of $\sigma_{1}^{2}=\sigma_{2}^{2}=\cdots \sigma_{k}^{2}$ is failed to reject [47]). It is worth nothing, for the cases that the ANOVA assumptions are not met, one can use data transformation methods or perform nonparametric test (e.g. Kruskal Wallis) [40]. The ANOVA assumption was met in the current case study examples with the summary of all the P-values provided in Table A3.

Table A1. ANOVA results between the biaxial tension and simultaneous biaxial-shear modes.

\begin{tabular}{ccccccc}
\hline $\begin{array}{c}\text { Sources of } \\
\text { Variation }\end{array}$ & $\begin{array}{c}\text { Sum } \\
\text { of Squares }\end{array}$ & $\begin{array}{c}\text { Degree of } \\
\text { Freedom }\end{array}$ & $\begin{array}{c}\text { Mean } \\
\text { Square }\end{array}$ & F-Ratio & P-Value & F $_{\text {crit }}$ \\
\hline Displacement level & 8263.951 & 7 & 1180.564 & 5.062 & 0.0139 & 3.787 \\
Deformation mode & 699.365 & 1 & 699.365 & 2.998 & 0.126 & 5.591 \\
Error & 1632.471 & 7 & 233.210 & & & \\
Total & 10595.791 & 15 & & & & \\
\hline
\end{tabular}

Table A2. Levene's test of equality of variances; The test rejects the hypothesis that the variances are equal if $\mathrm{F}>\mathrm{F} \alpha, k-1,(a-1)(b-1)$ where $\mathrm{F} \alpha, k-1, N-k$ is the upper critical value of the $\mathrm{F}$ distribution with $k-1$ (treatments) and $(a-1)(b-1)$ (error) degrees of freedom, at significance level of $a(5 \%)$ [44]. Here $a=2$ and $b=8$ corresponding to the number of levels of the deformation mode and displacement factors, respectively; $k$ is the total number of sample groups $(a \times b)$ in the two-way ANOVA test.

\begin{tabular}{cccc}
\hline F & DOF 1 & DOF 2 & P-Value \\
\hline 0.472 & 15 & 7 & 0.780 \\
\hline
\end{tabular}


Table A3. Summary of the P-values for each hypothesis testing of deformation modes.

\begin{tabular}{ccc}
\hline Deformation modes tested for the null hypothesis & \multicolumn{2}{c}{ P-Value } \\
Biaxial Warp vs Weft & Weft 0.025 & Warp 0.03 \\
Biaxial vs. simultaneous biaxial + PF & Weft 0.014 & Warp 0.001 \\
Biaxial vs. Simultaneous CS + PF+ biaxial & Weft 1.36e-05 & Warp 0.008 \\
Biaxial with 15 degree pre-PF shear vs. pure biaxial & W
\end{tabular}

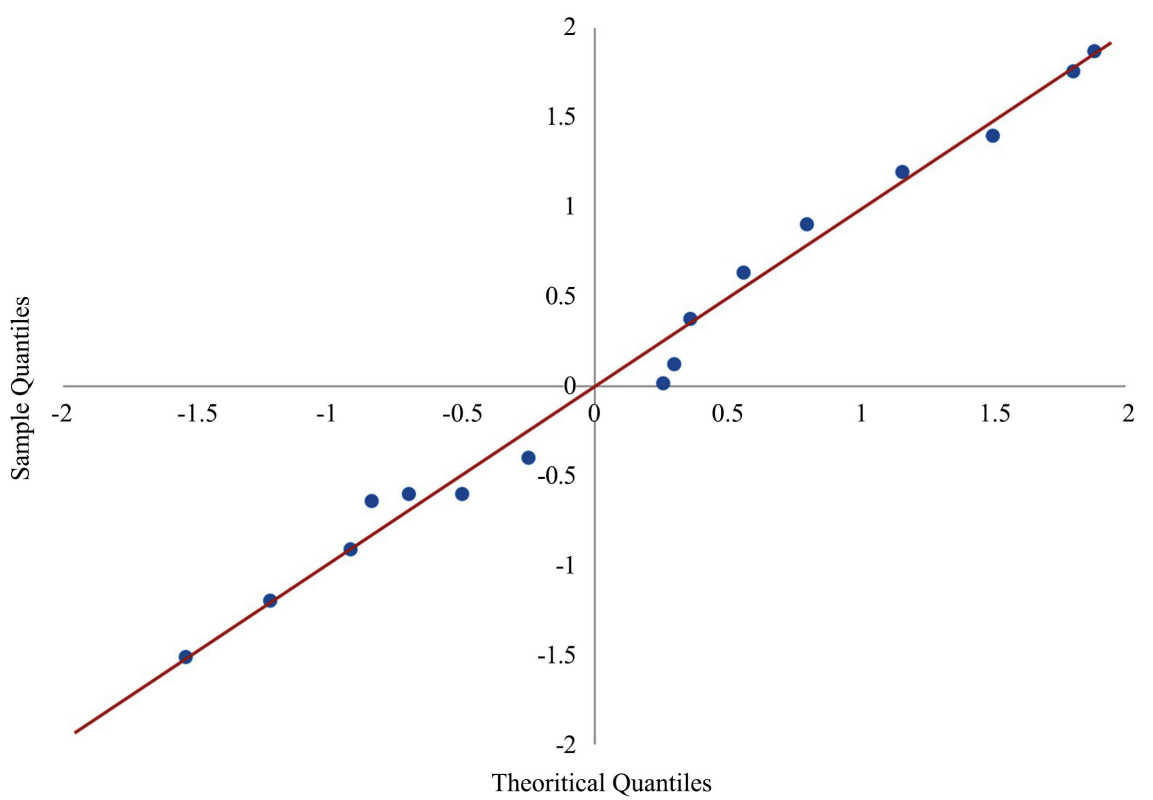

Figure A1. Normal Q-Q plot to assess the normality assumption of the biaxial-shear case in weft direction. 